\title{
Numerical simulation of radial compressor stages with seals and technological holes
}

\author{
Tomáš Syka ${ }^{1, a}$, Ondřej Luňáček ${ }^{2}$ and Jindřich Kňourek ${ }^{1}$ \\ ${ }^{1}$ University of West Bohemia, New Technologies - Research centre, 30614 Pilsen, Czech Republic \\ ${ }^{2} \breve{C}$ KD KOMPRESORY a. s., R\&D Department, 19002 Prague 9, Czech Republic
}

\begin{abstract}
Article describes numerical simulations of an air flow in radial compressor stages in the NUMECA CFD software. Four different radial compressor stages were solved in this article. During the tasks evaluating the stepped and straight impeller seals and technological holes influence on working characteristics and the flow field was observed. Also the CFD results comparison with results from the empiric design tool is described.
\end{abstract}

\section{Introduction}

All blade machines contain several features and construction modifications, which affect their working characteristics. The way of construction modifications design is often compromise with respect to machine operation, manufacturability and assembly. These factors are, of course, related to machine final price.

This article is about numerical simulations of radial compressor stages, where the main complications are connected to the appropriate design of seals areas, diffuser passage or possible technological holes in rotor blades.

The following text is divided into two themes. The first one deals with the influence of impeller seals presence on stage working characteristics and in the second one the influence of technological holes presence in impeller blades is investigated. As proved later both themes are interesting and it is useful to deal with them.

Compressor stages numerical simulations were solved in NUMECA FINE/Turbo software.

\section{Computed compressor stages}

Results obtained from numerical simulations of following radial compressor stages will be presented in this article. We solved four different stages and they are marked from RTK 01 to RTK 04 due to clear arrangement. These stages are different in the blade number and type in corresponding areas of compressor channel, in the compressor channel shape or in working parameters. The seals presence influence on working parameters was evaluated at all computed stages and the influence of the

\footnotetext{
atsyka@ntc.zcu.cz
}

technological hole in impeller blades was evaluated at stages RTK 02 and RTK 04.

\subsection{RTK 01 stage}

This stage is specific for the presence of an axial guidance device with regulatory blades in the compressor intake. Guidance device is used to ensure the proper impeller blades leading angle and to reduce compressor losses. In this case, simulations were solved only for one guidance blades location, when blades were located in the default position $0^{\circ}$.

The RTK 01 stage simulation was also done only for $7460 \mathrm{rpm}$ of the impeller, what corresponds to the relative small mass flow coefficient and the stage pressure ratio.

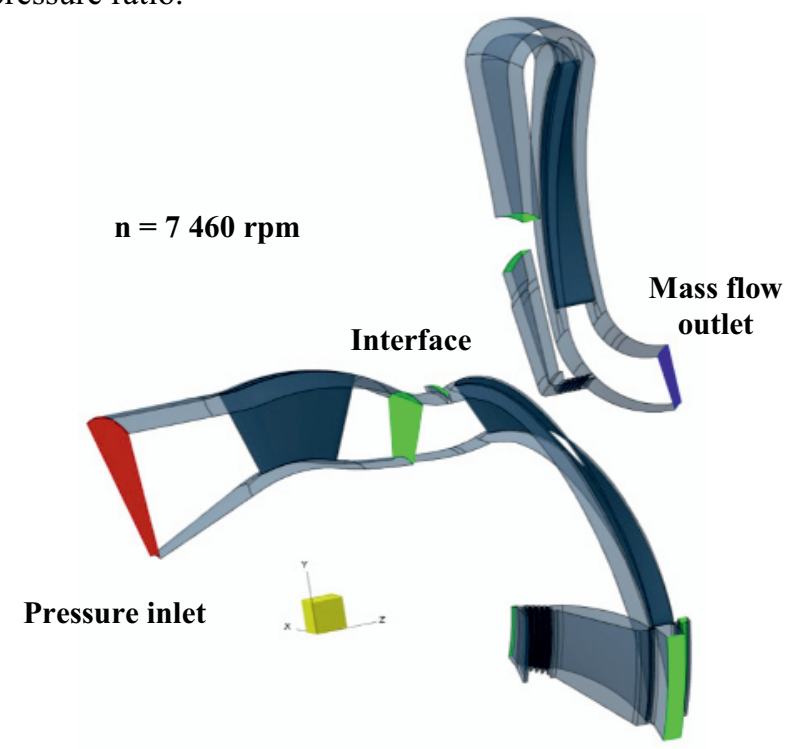

Figure 1. The RTK 01 stage model. 


\subsection{RTK 02 stage}

The compressor stage RTK 02 is the stage with the vaneless diffuser and without the axial guidance device. The stage model is atypical with the radial inlet, which substitutes return channel of previous stage in limited size. Impeller blades are 3D shaped and there are technological holes located at the impeller blades edge in the crossing between the blade and the cover disc.

Stage simulations were solved again only for one revolutions of the impeller - $13568 \mathrm{rpm}$. This stage works with relative big mass flow coefficient and pressure ratio.

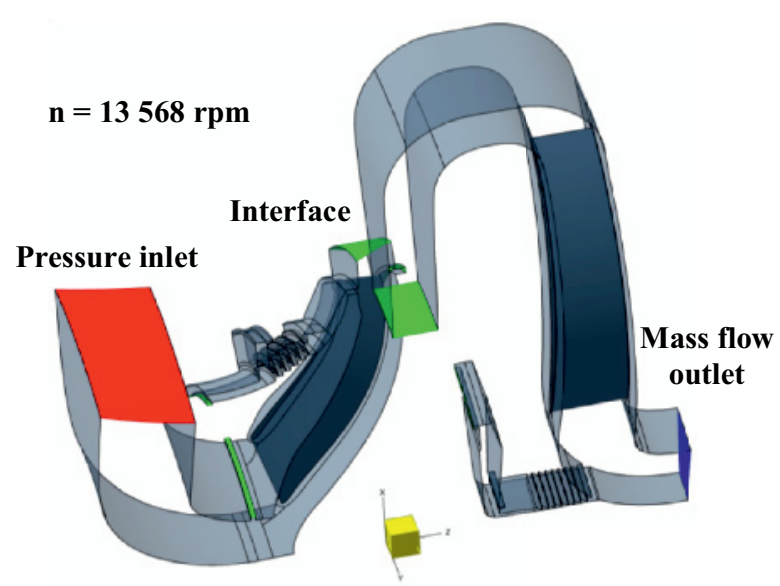

Figure 2. The RTK 02 stage model.

\subsection{RTK 03 stage}

The RTK 03 stage is very simmilar to the stage RTK 02 . RTK 03 is the modified variant of the stage RTK 02 with the narrower channel. Due to this the stage works with lower mass flow coefficients and reaches different pressure ratio values.

Basic construction parameters of the stage RTK 02 were kept - the number and the type of blades and operational revolutions.

\subsection{RTK 04 stage}

The same as stages RTK 02 and RTK 03 the stage RTK 04 has radial inlet into the stage model. The stage works with similar pressure ratio and mass flow coefficients like the RTK 01 stage, but has several diffuser blades.

RTK 04 stage is also different from previous ones because it has $2 \mathrm{D}$ shaped impeller blades and there are technological holes located approximately in the middle of the blades height. Working characteristics were investigated for two operational impeller revolutions 7476 and $15699 \mathrm{rpm}$.

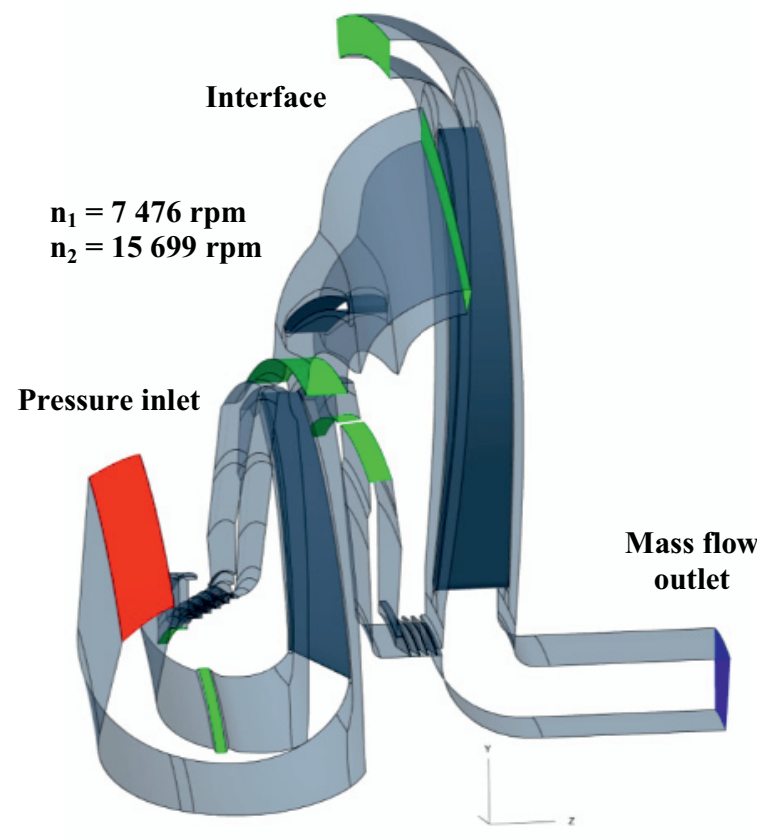

Figure 3. The RTK 04 stage model.

\section{Impeller seals influence}

Compressor stages numerical simulations with impeller seals had the task to reveal the seals influence on working characteristics of whole stages. Seals presence in the model is shown mainly like the impeller friction loss and loss by seals, where the amount of the heated and returning gas through stepped and straight seal is important. The losses presence consequence is the decreasing of the stages efficiency and the pressure ratio.

\subsection{Geometry and mesh creation}

The computational grid was created in the NUMECA TurboGrid software. The grid consists only of hexaedral cells and is block structured because of the computational time reduction.

As a base for computational grid creation the blades geometry, border curves of the stage channel and the impeller seals geometry are required from the complete 3D CAD stage model. This step was done in the ANSA software. ANSA is the suitable tool for the work with general surfaces and curves. For these and other benefits ANSA is being used in the automotive industry for creating and modifying of very complex geometry models. For the creation of the channel grid only one blade from each row is needed.

After import of the prepared geometry into NUMECA/AutoGrid environment the definition of border curves is required. It means assigning certain curves to the hub and the shroud of the channel. Similar process is used for the definition of blades. After setting up of several parameters like the number of blades and the number of grid elements generating of the block structured computational grid is possible. 
For the obtaining of undistorted results is necessary to keep the grid fine enough and also is necessary to keep certain grid cell properties, which are orthogonality $(>20)$, expansion factor $(<3)$ or aspect ratio $(<3000)$.

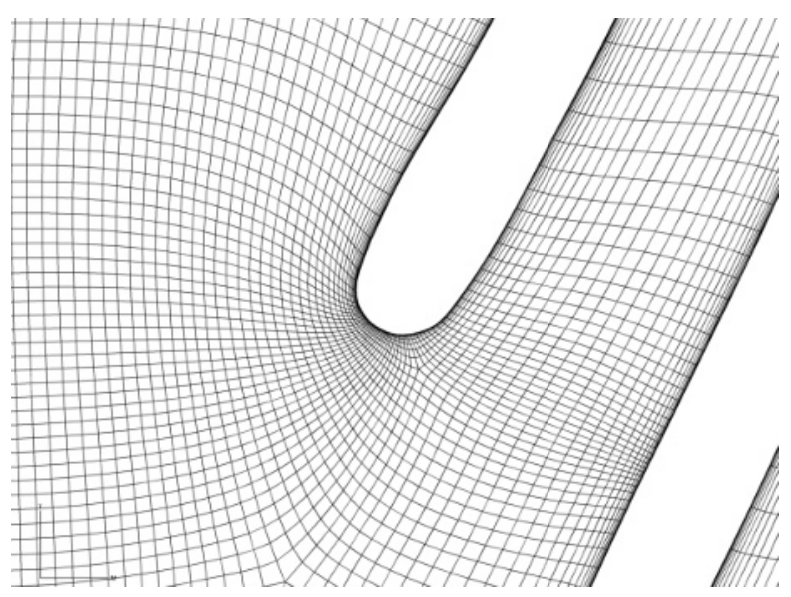

Figure 4. The detail of the impeller blades grid.

Base computational grids of all variants without seals consisted approximately of 3000000 hexaedral cells and variants with seals consisted approximately of 5000000 cells. The grid structure in the channel area is in both variants (with and without seals) identical because of the best possible results comparison. Thanks to very small height of cells at the walls $(0.005 \mathrm{~mm})$ it was possible to reach maximal $\mathrm{y}^{+}$around 10 in all solved computations.

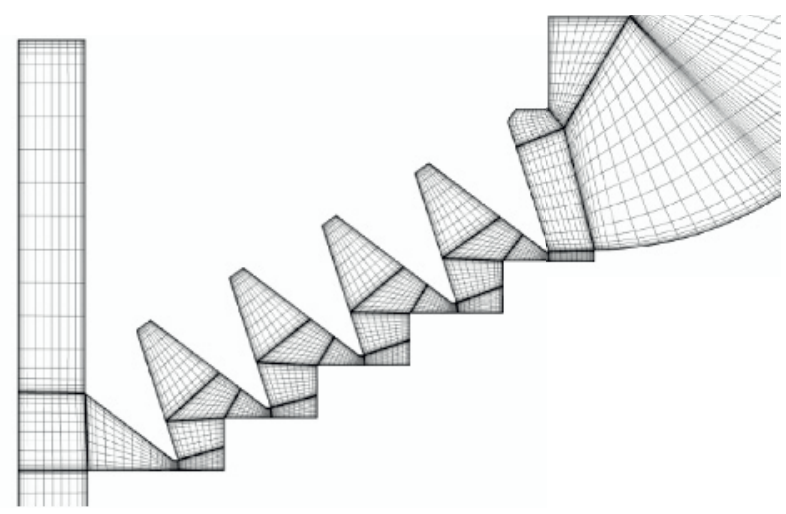

Figure 5. The detail of the stepped seals grid.

All stages were modeled with the pressure inlet boundary condition on the stage inlet and the mass flow outlet boundary condition on the outlet from the return channel. The boundary between specific functional model areas are defined as the mixing plane interface. Thanks to that we were able to reduce the number of blades to one in the each compressor stage area.

Pressurized medium is in our case air - ideal compressible gas. The SST k- $\omega$ turbulence model was used and cases were computed stationary.

\subsection{Efficiency and pressure ratio characteristics}

As was mentioned the operational range of the compressor stage is defined its characteristics, where the most important parameters are values of the efficiency and the pressure ratio depending on the mass flow of the pressurized gas through the stage. In following graphs are shown working characteristics of simulated stages depending on the mass flow coefficient.

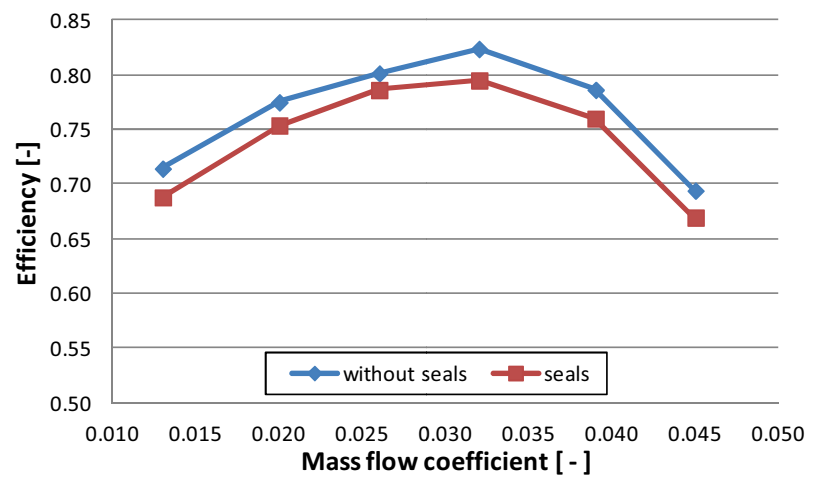

Figure 6. The RTK 01 stage efficiency - $7460 \mathrm{rpm}$.

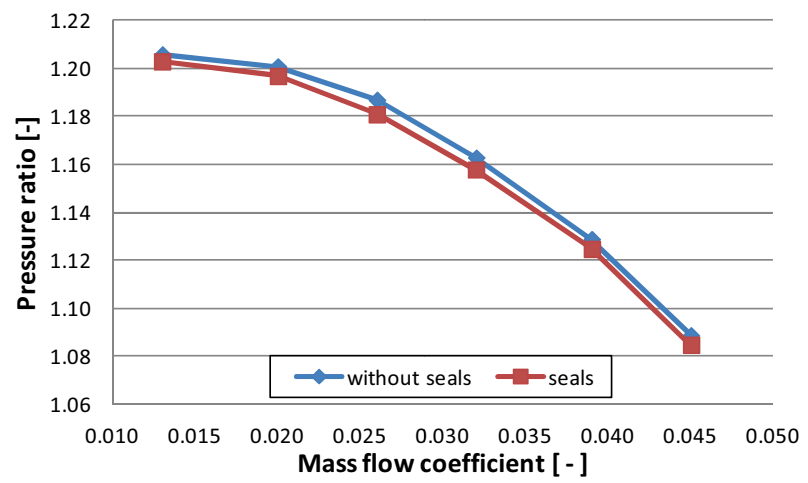

Figure 7. The RTK 01 stage pressure ratio - $7460 \mathrm{rpm}$.

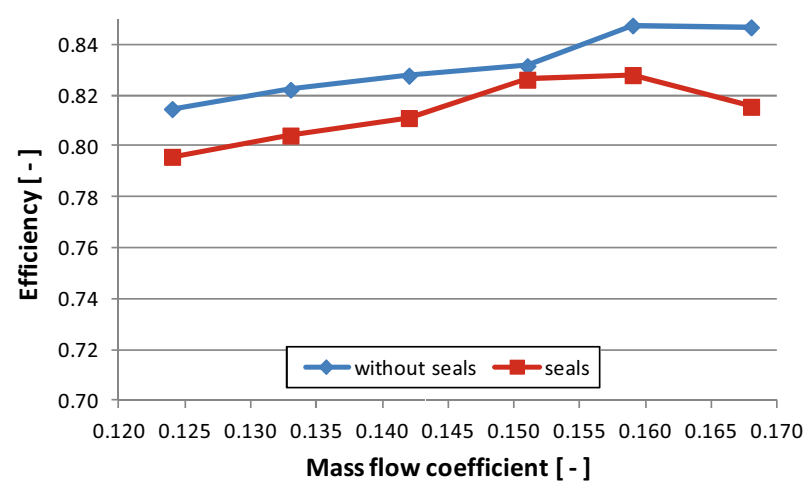

Figure 8. The RTK 02 stage efficiency - $13568 \mathrm{rpm}$. 


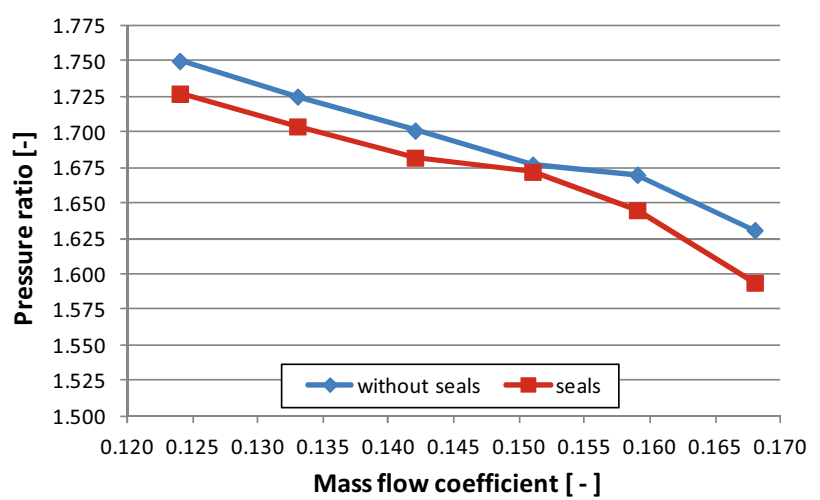

Figure 9. The RTK 02 stage pressure ratio - $13568 \mathrm{rpm}$.

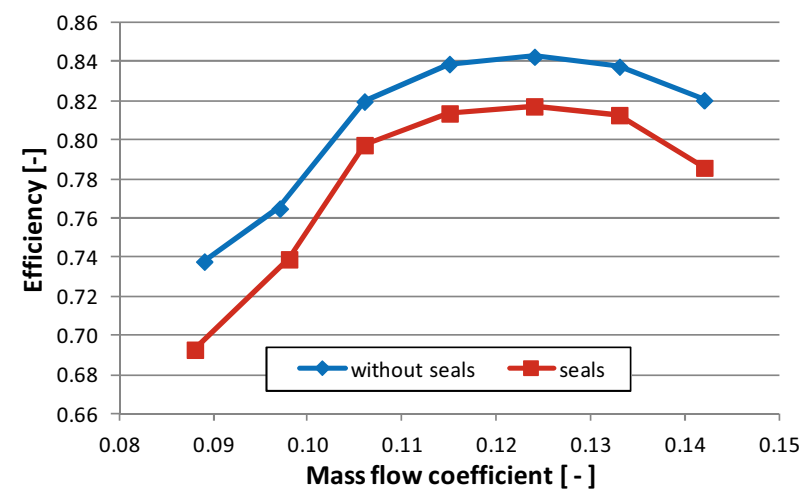

Figure 10. The RTK 03 stage efficiency - 13568 rpm.

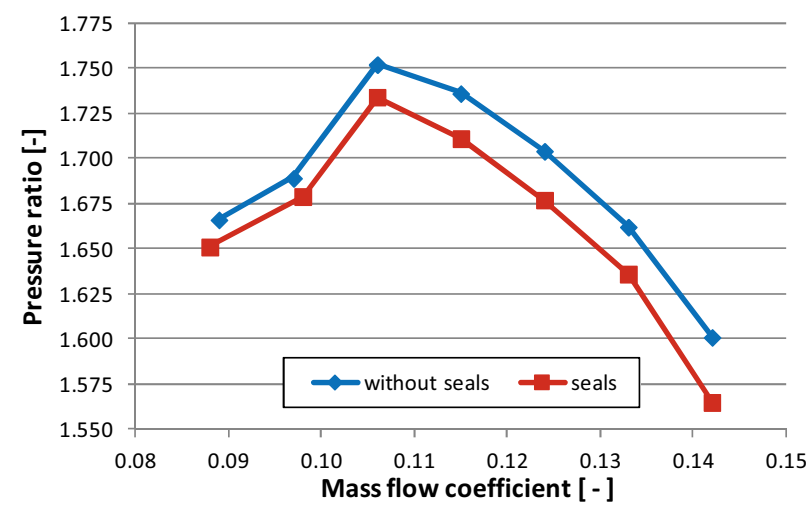

Figure 11. The RTK 03 stage pressure ratio - $13568 \mathrm{rpm}$.

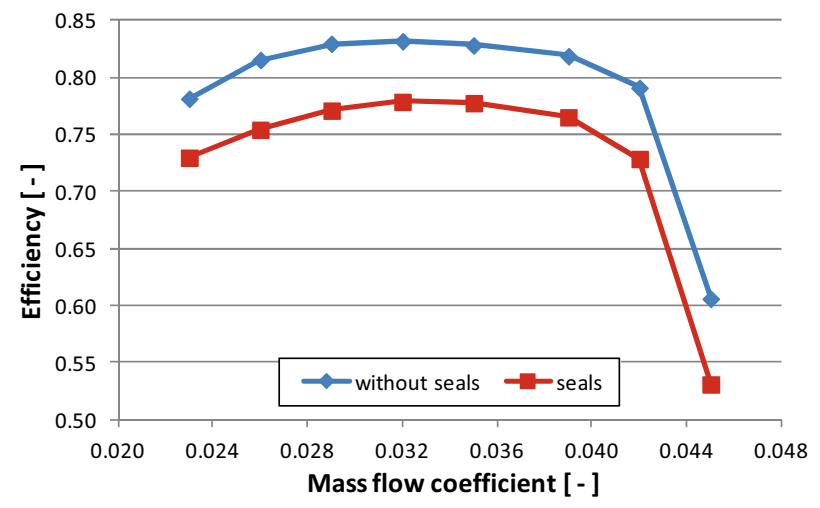

Figure 12. The RTK 04 stage efficiency - 7476 rpm.

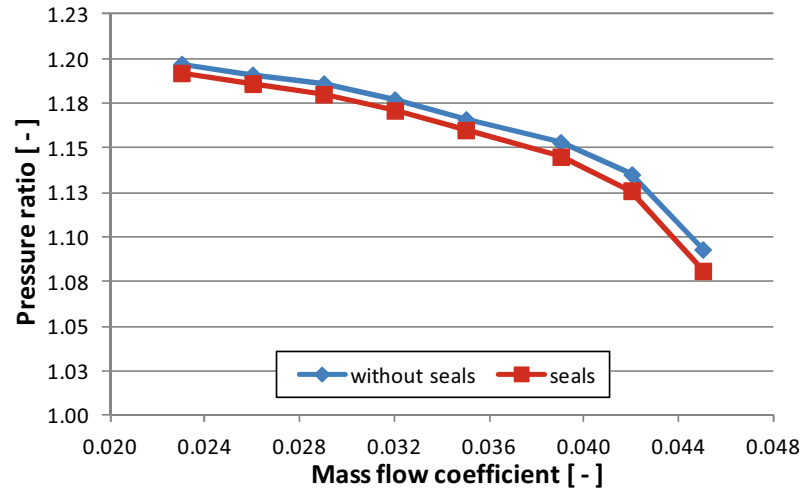

Figure 13. The RTK 04 stage pressure ratio - $7476 \mathrm{rpm}$.

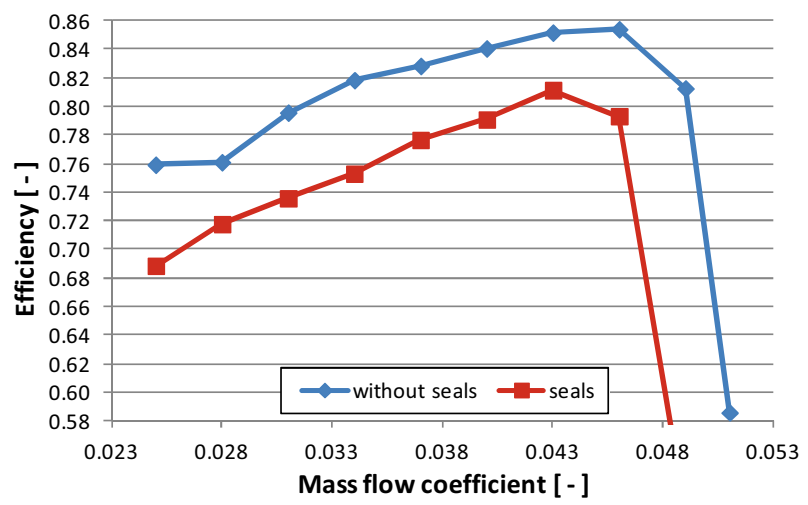

Figure 14. The RTK 04 stage efficiency - 15699 rpm.

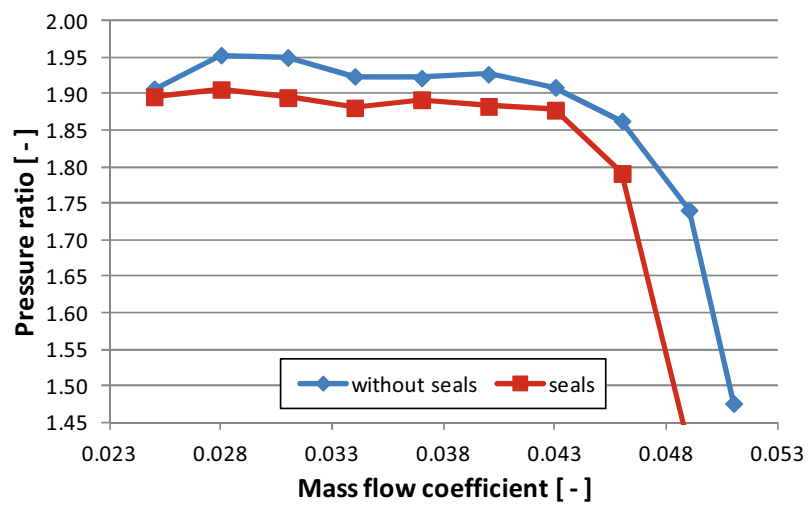

Figure 15. The RTK 04 stage pressure ratio - $15699 \mathrm{rpm}$.

From shown characteristics is obvious that the efficiency decrease is approximately $2 \%$ at the most solved stages and it is in accordance with the pressure ratio decrease. The exception is the stage RTK 04, where efficiency and pressure ratio decrease is bigger. The efficiency decrease is between 4 to $5 \%$ in both solved regimes with different revolutions, which is interesting because the stage RTK 04 has similar design, revolutions and working parameters as the stage RTK 01, where the efficiency decrease caused by presence of seals isn't so big.

In the area of the seals design these stages differs in the number of straight seal edges in certain domains. For now the question is if the big efficiency decrease is caused by the different seals design or different loss in the diffuser. The research of the stage RTK 04 is still 
running in order to find out what causes the decrease of working parameters.

\subsection{Mass flow through impeller seals}

Seals losses are dependent on the amount of the pressured gas, which flows through seals back against the direction of the main flow in the channel. For the correct design of the seals edges shape and their number is required to know amount of gas, which flows through seals. In the following graphs is shown the comparison of mass flow values obtained from CFD simulations in NUMECA and values from the $1 \mathrm{D}$ empiric design tool (KSTK).

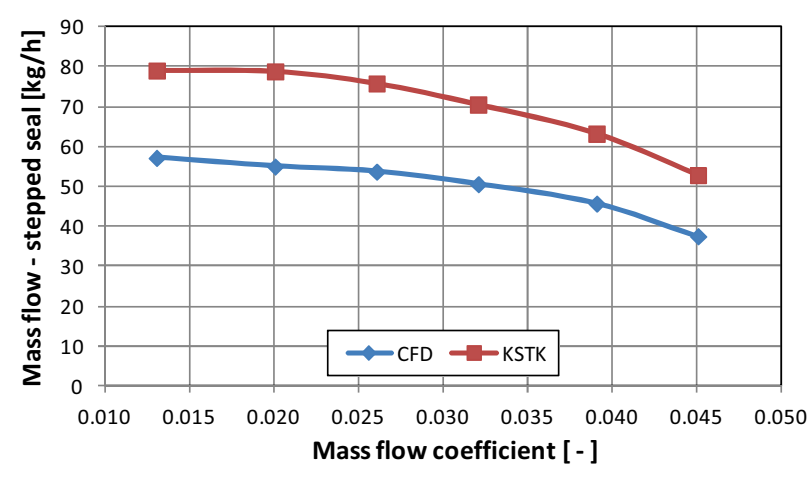

Figure 16. Mass flow in stepped seal - RTK 01, $7460 \mathrm{rpm}$.

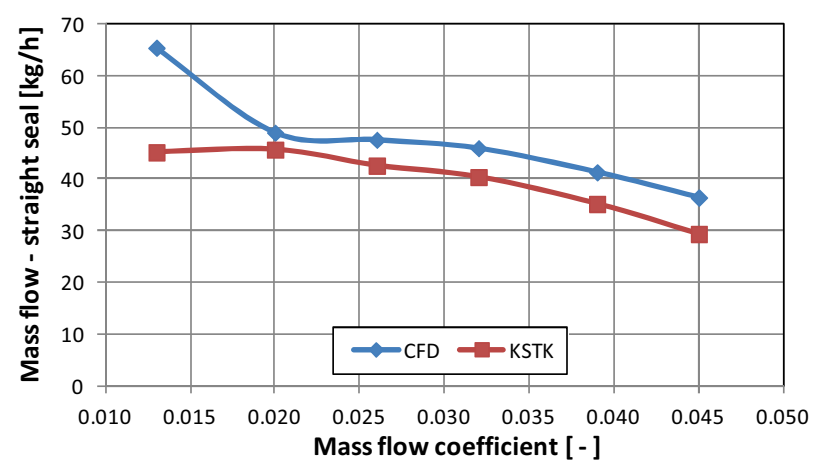

Figure 17. Mass flow in straight seal - RTK 01, $7460 \mathrm{rpm}$.

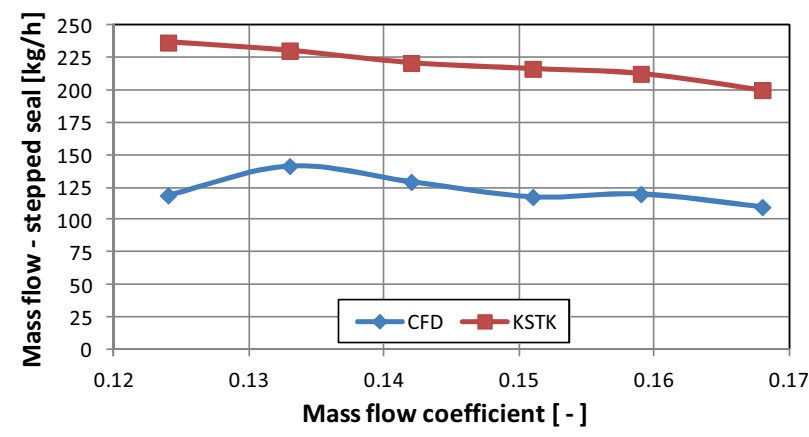

Figure 18. Mass flow in stepped seal - RTK 02, $13568 \mathrm{rpm}$.

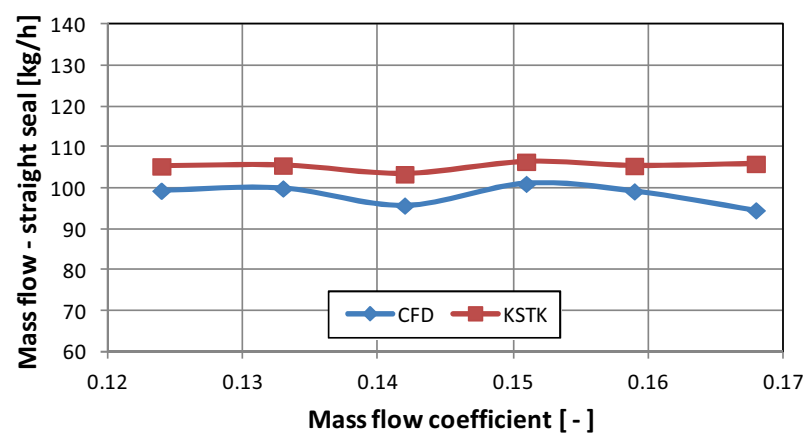

Figure 19. Mass flow in straight seal - RTK 02, $13568 \mathrm{rpm}$.

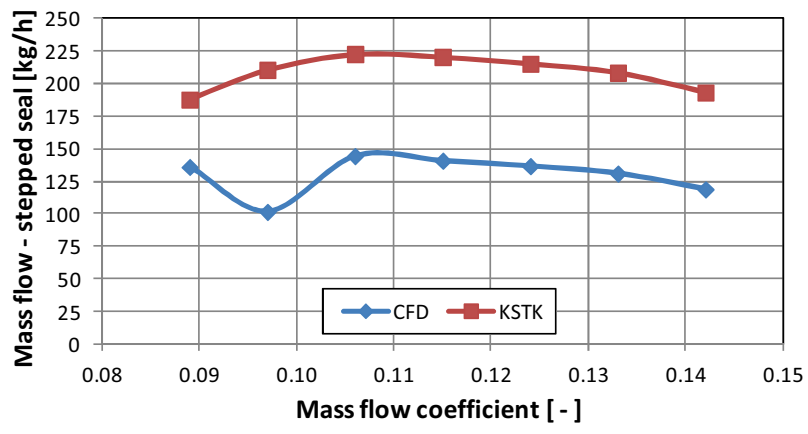

Figure 20. Mass flow in stepped seal - RTK 03, $13568 \mathrm{rpm}$.

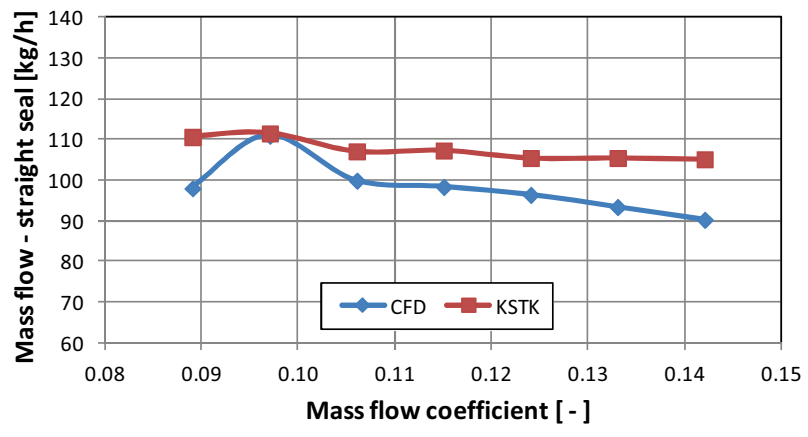

Figure 21. Mass flow in straight seal - RTK 03, $13568 \mathrm{rpm}$.

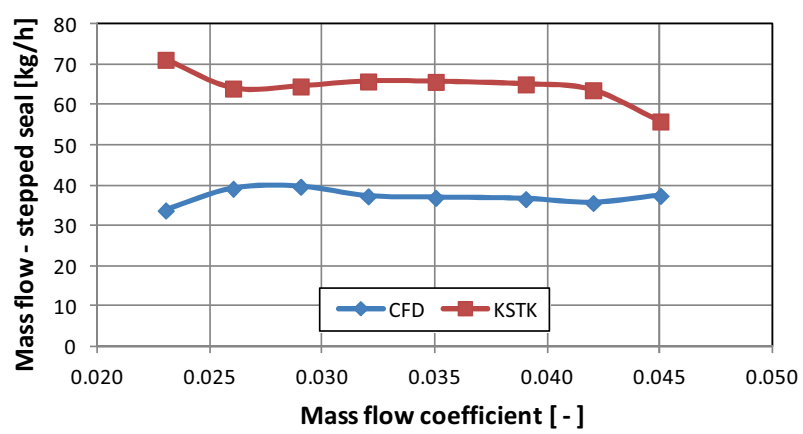

Figure 22. Mass flow in stepped seal - RTK 04, $7476 \mathrm{rpm}$. 


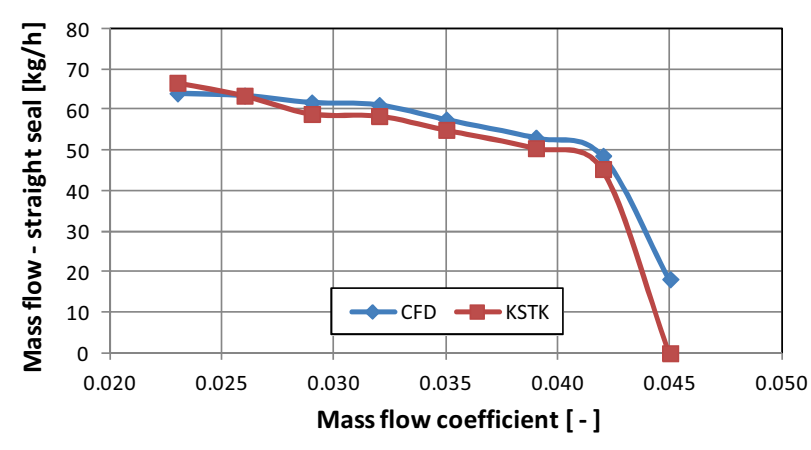

Figure 23. Mass flow in straight seal - RTK 04, $7476 \mathrm{rpm}$.

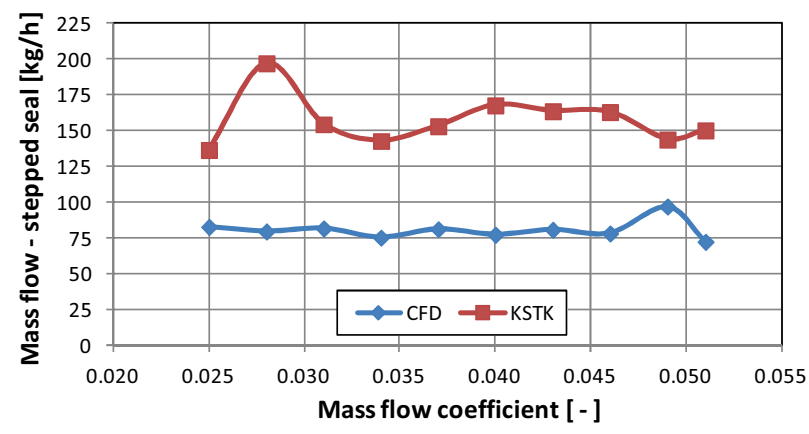

Figure 24. Mass flow in stepped seal - RTK 04, 15699 rpm.

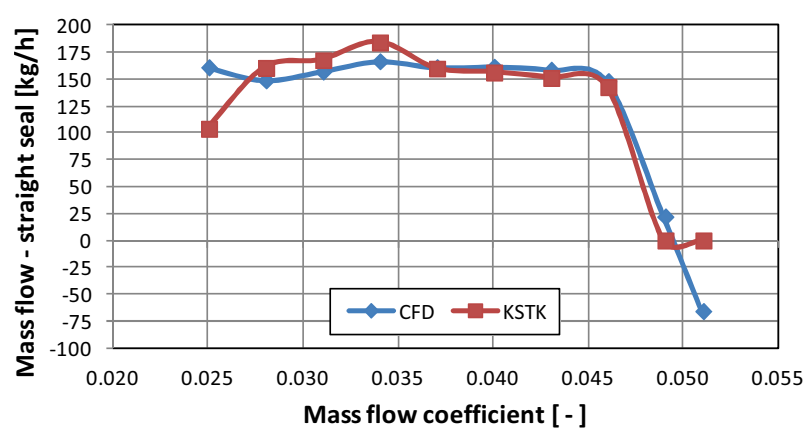

Figure 25. Mass flow in straight seal - RTK 04, 15699 rpm.

After evaluation of the mass flow going through the seals from numerical simulations in NUMECA it is obvious that mass flow in the stepped seals area is bigger than the mass flow determined by the KSTK tool at all solved stages. In comparison with straight seals, there is different situation. Values obtained from the KSTK tool are very near to results from NUMECA simulations.

During evaluation of the RTK 04 stage was found out that when the compressor stage was running with higher revolutions $(15699 \mathrm{rpm})$ and in the area of the low pressure ratio, the mass flow in straight seals was approximately zero or with the negative direction.

\section{Technological hole influence}

Impellers can be manufactured by several ways. In order to achieve the most accurate impeller dimensions and fine surface quality can be used electric discharge machining, but this method is very expensive therefore the combination of milling and welding is being used in most cases. The hole in impeller blades is in this case the technological blades modification used during welding manufacturing. Welded impellers consist of cover and carrier disc and their connection is made in the specific impeller blades height. So the hole is created during impeller assembling and it is the prevention from the local tension concentration.

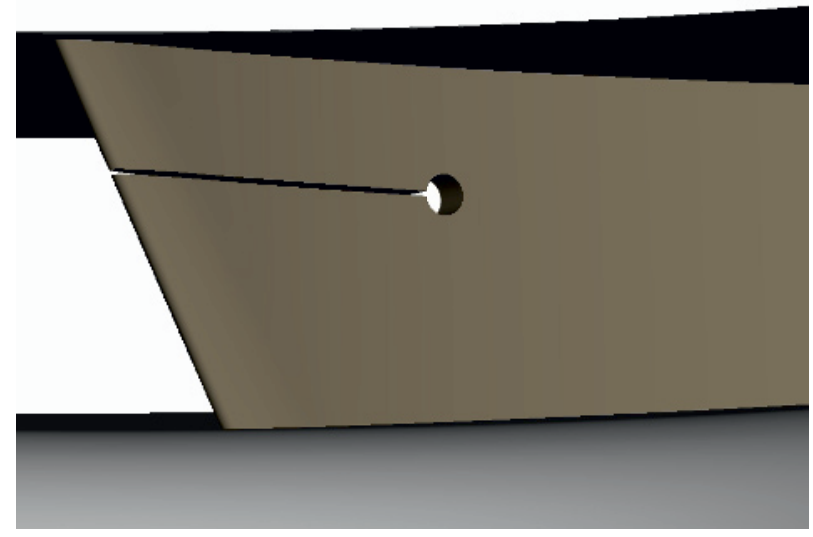

Figure 26. The technological hole in the impeller blade.

In the figure 26 the example of the technological hole design is shown (RTK 04). The technological hole is located approximately in the middle of the blade height in this case but the hole can be located at the blades edge in the crossing between the blade and the cover disc too.

In this context there is a question how significant influence has this technological hole on the compressor stage efficiency and the pressure ratio. The basic assumption is that the efficiency and the pressure ratio should decrease due to the flowing of some amount of the pressurized gas from the pressure side to the suction side of impeller blades what is followed by the certain influencing of the flow field between impeller blades.

If it turns out that the influencing of working characteristics is large it should be considered during the compressor stage design.

\subsection{The mesh of the technological hole}

The technological hole grid creation is more complicated and difficult than the creation of the main channel mesh because the manual work is required. In the AutoGrid environment it is possible to create technological holes automatically but this tool is determined to turbine stages. Due to the block structured grid which NUMECA uses the inserting of technological hole grid blocks and their connection definition with the main channel is required.

There are two ways to connect the hole mesh to the main one. Both methods have the same principle of the connection but the connection location is different. Connection of the hole mesh is provided by the „interface“ boundary condition in both cases. In the first way the „interface“ is used on the pressure and the suction side of the impeller blade. Benefits of this method are in the easy geometry and mesh preparation and in the insignificant intervention to the main channel mesh. The main disadvantage can be the big difference of the cell density in the area of the connection. 
In the second method of the mesh connection „interface“ boundary conditions were moved to the greater distance from the technological hole area. The main benefit is the precise hole edge definition in the model but there are large interventions to the main stage mesh which increase the amount of work involved and the is also local higher cell density around the technological hole area.

Both ways of the mesh creation were tested on numerical simulations of the compressor stage RTK 04. The stage efficiency and pressure ratio decrease was important to us. Simulations were done on geometric variants with and without the technological hole.

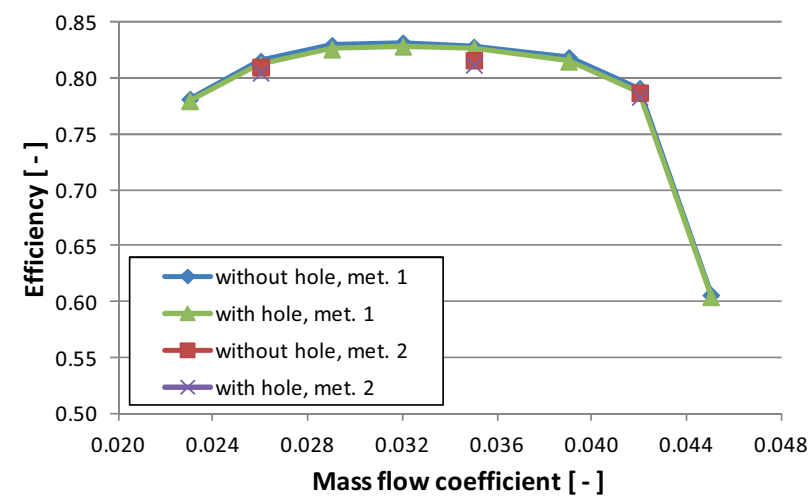

Figure 27. The RTK 04 stage efficiency - 7476 rpm.

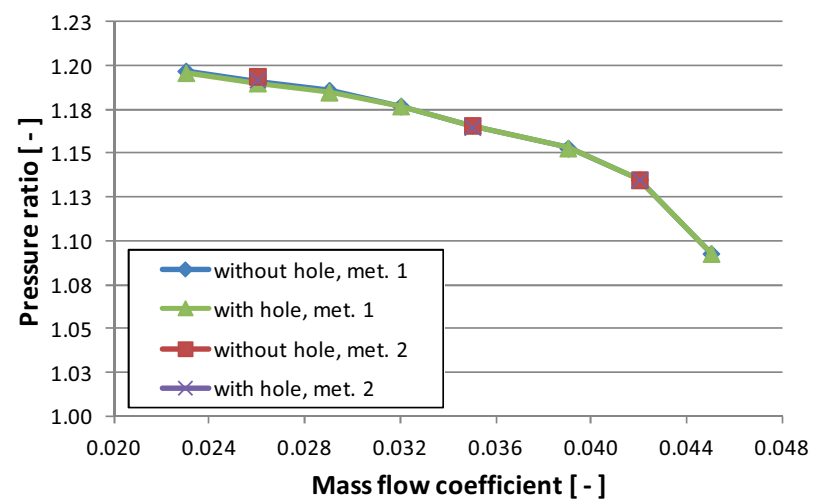

Figure 28. The RTK 04 stage pressure ratio - $7476 \mathrm{rpm}$.

In figures 27 and 28 are shown efficiency and pressure ratio characteristics depending on the RTK 04 stage mass flow coefficient for $7476 \mathrm{rpm}$. From results it is obvious that the technological hole influence on stage working characteristics is in this case insignificant. Moreover it is shown that the hole mesh design influence is the same for both methods. Also small decrease of values due to local higher cell density is presented. The same differences depending on the mesh design were found in simulations with $15699 \mathrm{rpm}$.

\subsection{Working characteristics}

Following characteristics of stages RTK 02 and RTK 04 show the impeller blades technological hole influence. On the first sight it is obvious that in the case of $3 \mathrm{D}$ shaped impeller blades of the RTK 02 stage is the hole influence great and variable but in the case of $2 \mathrm{D}$ shaped impeller blades of the RTK 04 the influence on the working characteristics is very small and constant.

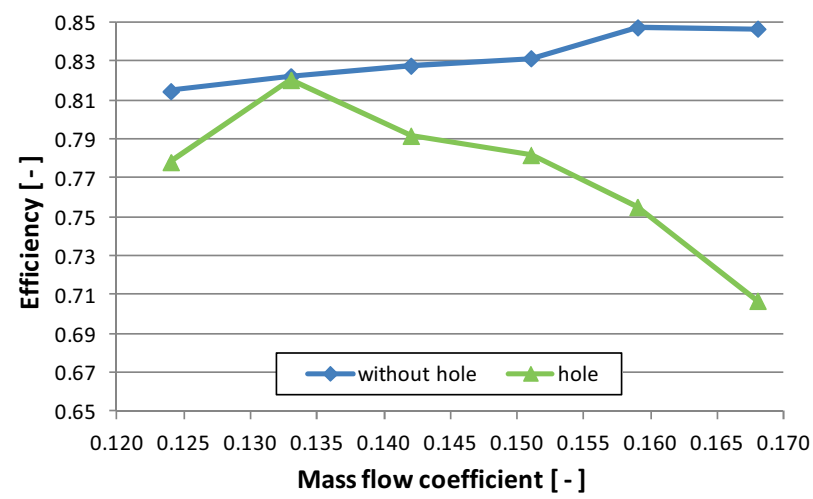

Figure 29. The RTK 02 stage efficiency - 13568 rpm.

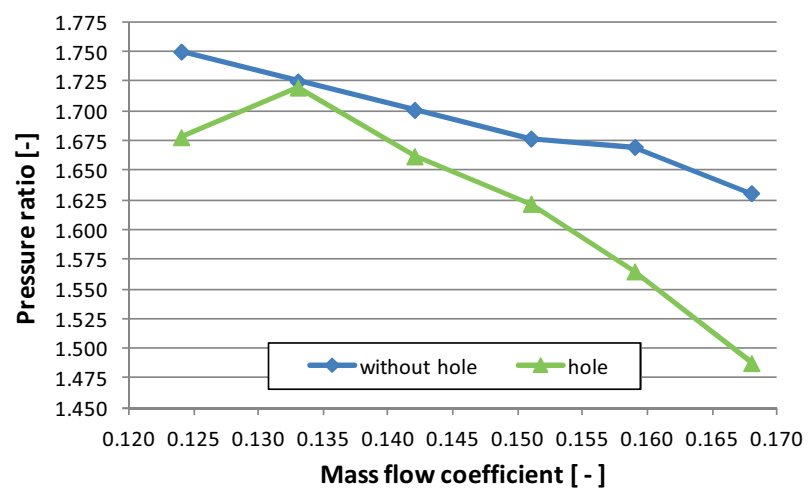

Figure 30. The RTK 02 stage efficiency - $13568 \mathrm{rpm}$.

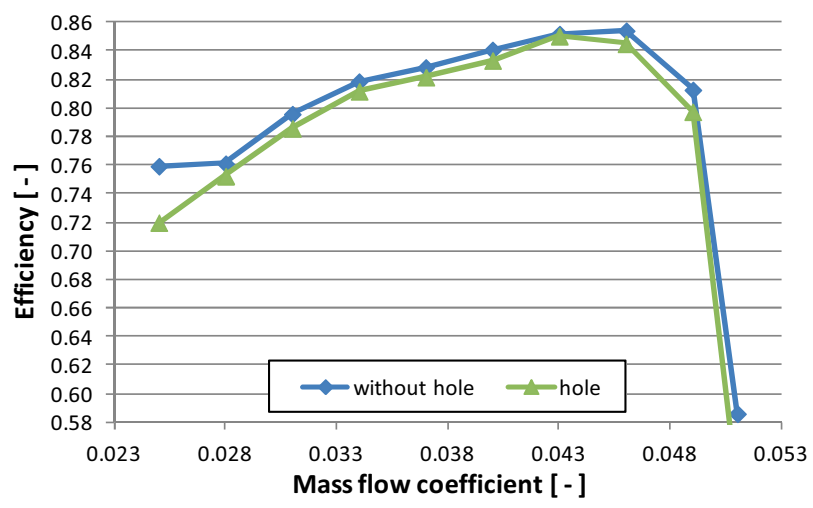

Figure 31. The RTK 04 stage efficiency - 15699 rpm.

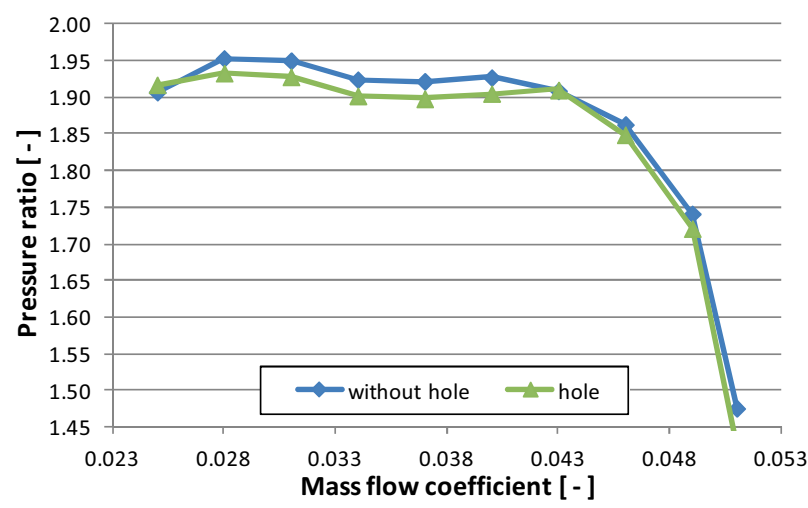

Figure 32. The RTK 04 stage efficiency - 15699 rpm. 
From results follows that the RTK 02 and RTK 04 stages with technological holes behavior is totally different. Presence of the hole in the RTK 02 stage has great impact on working characteristics depending on actual the mass flow. When the mass flow rises the technological hole influence rises too and the efficiency decrease is up to $12 \%$.

On the other hand the RTK 04 stage behavior is stable and consistent in all characteristics working points and the efficiency decrease is up to $1 \%$ in whole operating range. For the better evaluation of the situation in compressor stages streamlines from technological holes were drawn.

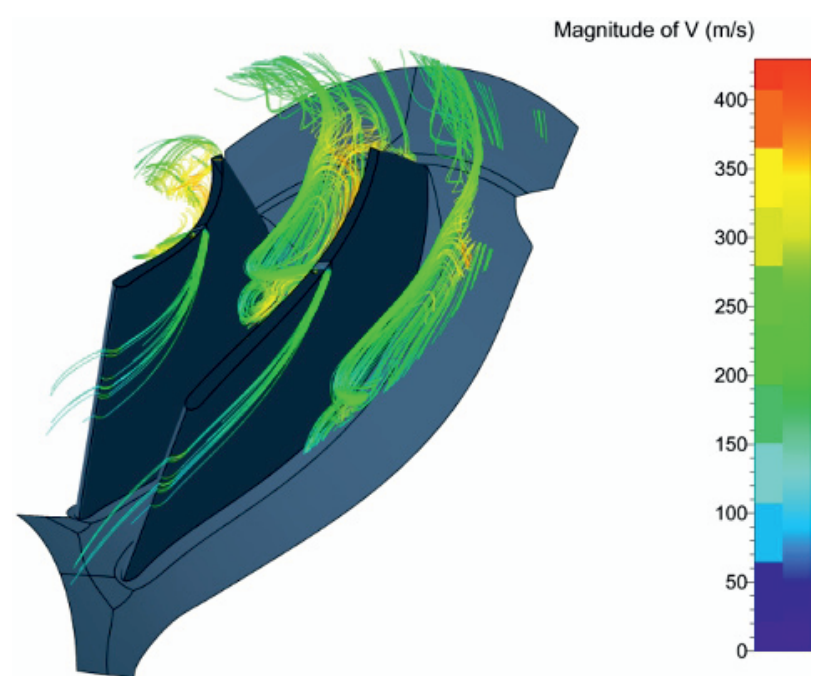

Figure 33. Streamlines in the impeller area - RTK 02.

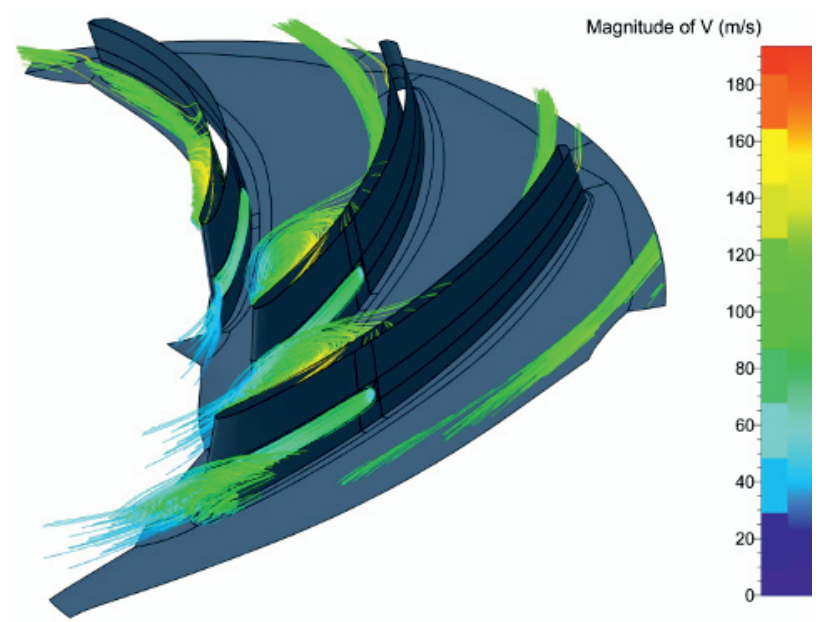

Figure 34. Streamlines in the impeller area - RTK 04.

Pictures show that flow character between impeller blades is totally different. In the RTK 02 stage is the massive flow separation from the blade surface. The flow separation influences velocity and pressure field up to the middle of the channel high on the impeller outlet.

The flow situation in the RTK 04 stage is much better. The separation is also presented but it isn't so large and copies the impeller blades suction side surface.

\section{Conclusions}

In this article was mainly investigated the influence of impeller seals and technological holes presence. It was found out that both design features have insignificant influence on the stage behavior and it is important to know their functional rules.

In the case of stepped and straight impeller seals is the influence on working characteristics more or less constant in all working points, but still the design of some stages has deficiencies which can cause unexpected results.

The situation with the technological holes design is similar. This area of interest is relatively unexplored and numerical simulations show that the inappropriate design of technological hole dimensions, location or orientation can cause the dramatically working parameters decrease in some specific situations.

\section{Acknowledgments}

The results were developed within the CENTEM project, reg. no. CZ.1.05/2.1.00/03.0088, co-funded by the ERDF as part of the Ministry of Education, Youth and Sports OP RDI programme and in the framework of the FR-TI3/421 project (TIP programme, Ministry of Industry and Trade of the Czech Republic) and specific research.

\section{References}

1. P. C. Hanlon, Compressor handbook (McGraw-Hill, USA, 2001)

2. J. Kadrnožka, Lopatkové stroje (CERM, Brno, 2003)

3. J. Kadrnožka, Tepelné turbiny a turbokompresory (CERM Brno, 2004)

4. J. Bečvář a kol., Tepelné turbíny (SNTL, Praha 1968)

5. M. P. Boyce, Principles of Operation and Performance Estimation of Centrifugal Compressors (Dallas, TX., 1993) 